\title{
IDENTIFICAÇÃO DE PATOLOGIAS EM FACHADAS E METODOLOGIA DE ANÁLISE: ESTUDOS DE CASOS NA UNIVERSIDADE FEDERAL DO PARÁ
}

\author{
Identification of pathologies in facades and analysis methodology: \\ case studies at the Federal University of Pará
}

\author{
Isabella Chaves Carvalho ${ }^{1}$, Marcelo de Souza Picanço ${ }^{2}$, Alcebíades Negrão Macedo ${ }^{3}$
}

Recebido em 22 de maio de 2014; recebido para revisão em 10 de julho de 2014; aceito em 15 de agosto de 2014; disponivel on-line em 08 de outubro de 2014.

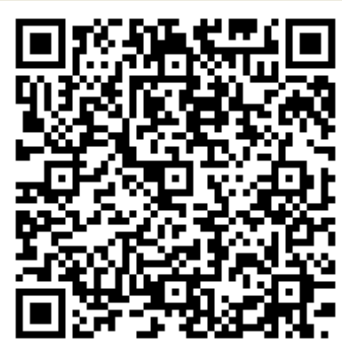

\section{PALAVRAS CHAVE:}

Patologias em fachadas;

Fichas de identificação de danos;

Mapa de danos.

\section{KEYWORDS:}

Facades pathologies; Damage identification form;

Map damage.

RESUMO: O sistema de revestimento externo da edificação funciona como camada de proteção e contribui para o bom aspecto da mesma. A fachada está sujeita à ação de agentes de degradação por ser uma das zonas mais expostas do edifício, com a presença de patologia tornando-se responsável por elevados custos de reparos. A pesquisa propõe, como objetivo, o levantamento das patologias existentes em fachadas de edificações da Universidade Federal do Pará, de modo a adquirir subsídios para executar futuras intervenções em equipamento público a partir da identificação dos principais problemas presentes nos estudos de caso. Para tal, partiu-se do desenvolvimento de métodos avaliativos para identificar de forma padronizada os danos relevantes, a partir da produção de documentos que facilitem processos de inspeções visuais com obtenção de informações dos danos. Como resultados da identificação de patologias em fachadas com sua respectiva metodologia de análise, esperou-se contribuir para o incremento de procedimentos que visem o desempenho técnico-econômico de fachadas como um todo, auxiliando em futuras manutenções das edificações em análise, assim como produção de fonte de consulta para outros empreendimentos.

ABSTRACT: The system of external cladding of the building acts as a protective layer and contributes to the proper aspect. The facade is subject to the action of agents of degradation as one of the most exposed areas of the building, with the presence of pathology becoming responsible for high repair costs. Research suggests as a goal, a survey on of buildings facades in the Federal University of Pará, to acquire grants to run future interventions in public facilities from the identification of the main problems present in the case studies. Started the development of evaluation methods to identify the damage with a standardized manner from the document production that facilitate visual inspections with obtaining information from damage. From the result of the identification of pathologies in facades with their respective methods of analysis, was expected to contribute to the increase in procedures that seek technical and economic performance of façades as a whole, assisting in future maintenance of the buildings in question, as well as production of reference source for other ventures.

\footnotetext{
* Contato com os autores:
}

${ }^{1}$ e-mail : carvalho.bella@gmail.com

( I.C. Carvalho )

Mestre em Engenharia Civil, Instituto de Tecnologia da Universidade Federal do Pará (ITEC/UFPa).

22e-mail : marcelopicanco2004@yahoo.com.br (M. S. Picanço )

Doutor em Geologia e Geoquímica, Professor da Faculdade de Engenharia Civil do Instituto de Tecnologia da Universidade Federal do Pará, (FEC/ITEC/UFPa).

${ }^{3}$ e-mail : anmacedo@ufpa.br

( A. N. Macedo )

Doutor em Engenharia de Estruturas, Professor da Faculdade de Engenharia Civil do Instituto de Tecnologia da Universidade Federal do Pará, (FEC/ITEC/UFPa). 


\section{INTRODUÇÃO}

Os revestimentos externos funcionam para a edificação como a primeira camada de proteção contra agentes ambientais, sendo, portanto, elementos que precisam ter suas características respeitadas ou, pelo menos, ser de fácil substituição/manutenção, visando um nível mínimo de desempenho (SILVA, BRITO e GASPAR, 2011). Conforme explicita Flores-Colen e Brito (2010), a aparência da edificação torna-se relevante para a vida útil dos sistemas de revestimento, devendo apresentar requisitos de qualidade associados a baixos níveis de degradação. Tais requisitos mínimos, conforme Rodrigues, Teixeira e Cardoso (2011), estão relacionados com a capacidade que o envelope da edificação apresenta em garantir durabilidade e resistência à agentes externos, equilibrando a qualidade e conduzindo a baixos custos com manutenção.

A presença de patologias em fachadas é responsável por elevados custos de reparos, daí a importância em se preocupar com a maneira como acontecem os processos executivos. Segundo Censos (2001) $)^{1}$, Watt DS $(1999)^{2}$ e Qualité, progressons ensemble $(2006)^{3}$ apud Rodrigues, Teixeira e Cardoso (2011), esta preocupação se deve à incidência de danos em fachadas apresentarem cerca de $50 \%$ dos registros das patologias totais que afetam negativamente as edificações.

É comum, em obras públicas no Brasil, o aparecimento de uma sucessão de erros já decorrentes em obras anteriores por conta da falta de registros de informações, o que gera gastos financeiros com manutenção corretiva (COSTA JÚNIOR, 2001) que poderiam ser direcionados para outros fins que não fossem os de manutenção corretiva.
Além da ausência de cobrança no caso de ocorrência de falhas de execução (o profissional responsável deve responder pelo projeto por no mínimo cinco anos após sua construção), outro agravante de obras públicas está em como são iniciadas: segundo a Lei no 8.666 (1993), tais obras são realizadas mediante licitação com a aprovação apenas do projeto básico, em que o projeto executivo (mais completo e com correções necessárias) pode ser desenvolvido concomitantemente com a execução da referente obra. Assim, a solução de uma provável presença de falhas acontece quando a obra já está em andamento, podendo acarretar em tomadas de decisões emergenciais e sem planejamento que comprometem a qualidade do produto final e elevam os gastos financeiros.

As edificações diferem-se de outro produto porque são construídas para atender seus usuários durante anos, devendo apresentar condições adequadas ao uso durante seu tempo de serviço NBR 5674, ABNT (1999). A NBR 15575-1, ABNT (2013) aborda que a vida útil de projeto ${ }^{4}$ para sistemas de vedação vertical externa deve estar entre 40 a 60 anos, desde que se realize ações de manutenção. Do contrário, o revestimento pode ser seriamente comprometido, resultando em patologias por uso inadequado e não por falha de construção.

Edificações mais específicas, como as de ensino público, são indicadas para estudo em virtude da função social que representam, por trabalhar com formação de pessoas; e pela facilidade em desenvolver projetos educacionais baseados em diagnóstico de ambientes similares onde já ocorreram patologias, para entender o comportamento de seus elementos (CINTRA, 2001). Acredita-se que dados técnicos fundamentados em obras já executadas são capazes de auxiliar no desenvolvimento de

\footnotetext{
${ }^{1}$ Censos 2001: resultados definitivos: XIV recenseamento geral da população: IV recenseamento geral da habitação. INE, $1 \_$ volume, Lisboa, Portugal; 2001-a.

${ }^{2}$ Watt DS. Building pathology-principles \& practice. London: Blackwell Science; 1999.

${ }^{3}$ Qualité, progressons ensemble. Bilan 1995-2005. Agence Qualité Construction. Observatoire de la Qualité de la Construction; 2006.

${ }^{4}$ Período estimado para o qual um sistema é projetado para atender requisitos de desempenho, considerando conhecimento do projeto e supondo cumprimento da dos processos de manutenção (NBR 15575-1, 2013).
} 
projetos mais recentes (Barros e Sabbatini, 2001), utilizando aspectos patológicos já ocorridos como forma de planejamento para projetos futuros.

Para manter prédios públicos de ensino, como os existentes na Universidade Federal do Pará (UFPa), em condições ideais de funcionamento é preciso desembolso de recursos financeiros, o que nem sempre é facilmente viável quando se trata de obras coletivas de uso público. Isso justifica a necessidade do conhecimento dos danos presentes no local, para que em um segundo momento se proponha métodos para evitá-los; principalmente para edificações na UFPa, as quais estão constantemente sujeitas à ambientes extremamente agressivos em virtude de sua localização caracterizar-se por um clima quente e úmido, com chuvas associadas a elevadas temperaturas locais.

Dentro deste contexto, é relevante ter-se como objetivo geral do artigo o levantamento das patologias existentes em fachadas de edificações da Universidade Federal do Pará (campus Guamá Belém), de modo a adquirir subsídios para futuras intervenções em equipamento público a partir desta identificação dos principais problemas encontrados nos estudos de caso.

Para tal, conforme explicitado em item posterior, partiu-se do desenvolvimento de métodos avaliativos com o intuito de identificar de forma padronizada (recomendação da NBR 5674/99) os danos de significativa incidência, a partir da produção de documentos e diretrizes que facilitem processos de inspeções visuais com obtenção de informações dos danos.

Como resultados da identificação de patologias em fachadas com sua respectiva metodologia de análise, esperou-se contribuir para o incremento de procedimentos que visem o desempenho técnico-econômico de fachadas como um todo, auxiliando nas futuras manutenções das edificações estudadas, assim como na produção de fonte de consulta para outros empreendimentos.

\section{MATERIAIS E MÉTODOS}

Para o processo de identificação de patologias em fachadas, utilizando-se edificações da UFPa como exemplos, fez-se uso de metodologia de análise baseada em observações visuais (visitas técnicas exploratórias em edificações definidas com idades recentes, intermediárias e antigas) para detectar seus mecanismos de degradação (fissuras, perda de aderência, descolamento, eflorescência, umidade, mancha e corrosão em estrutura de concreto armado).

Apesar das observações visuais apresentarem facilidade de execução de operação local, apenas este tipo de avaliação apontaria como desvantagem possíveis subjetividades nas análises, podendo ser superado com uma metodologia de investigação centrada na impessoalidade e em dados consistentes. Para tal, visando direcionar as inspeções, foram aplicados instrumentos para a busca de dados de um grupo de edificações, baseando-se em modelos de pesquisas anteriores e que foram adaptados para os objetivos do estudo.

A partir de metodologia de análise pautada na padronização de etapas, apresenta-se as fases que são necessárias para identificação de patologias:

- Ficha de Identificação de Danos (FID): levantamento das características físicas e identificação de alterações existentes;

- Mapas de danos: mapeamento dos danos de edificações específicas de interesse para estudo, permitindo cruzamento de suas informações com as presentes nas fichas;

- Estudo comparativo da frequência de ocorrência dos danos: estabelece os danos mais recorrentes dentro da amostragem estipulada;

- Outros métodos: ensaios de caracterização de amostras e processos de intervenção

\section{1 ÁREA DE ESTUDO}

A área de estudo compreende 30 edificações, distribuídas nos três setores da UFPa, conforme observado no mapa de urbanização do campus, na Figura 1 abaixo. 


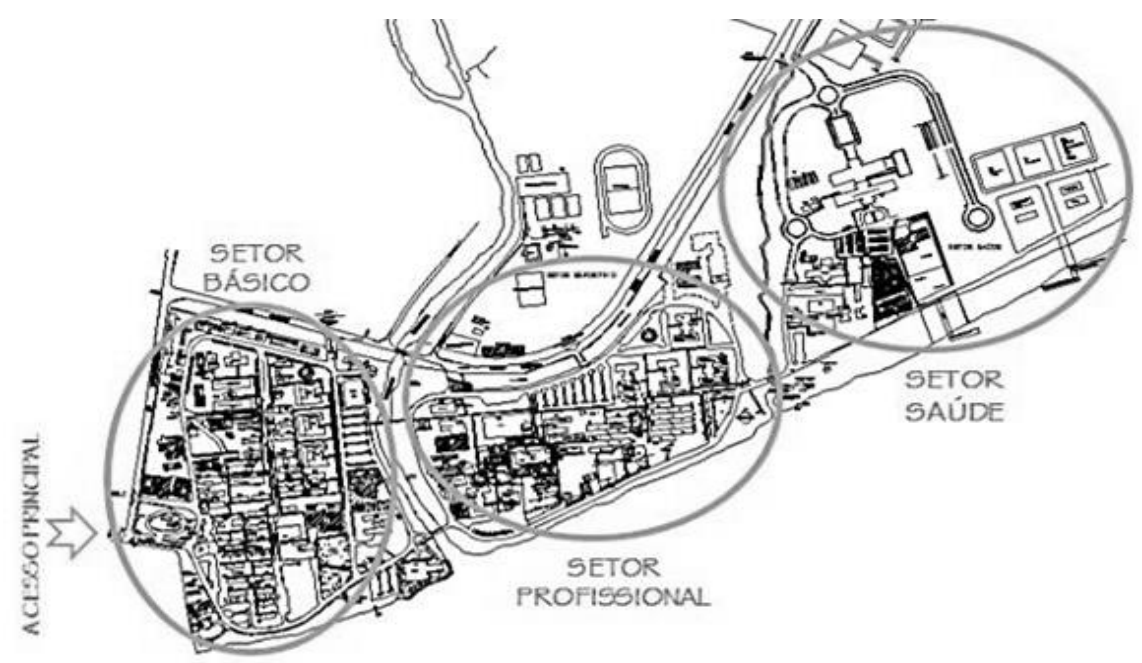

FIGURA 1: Planta de urbanização do campus Guamá da Universidade Federal do Pará FONTE: Adaptado de Coordenadoria de Projetos - CPO/UFPA, outubro - 2013.

\subsection{CRITÉRIOS DE ESCOLHA DAS EDIFICAÇÕES}

Com a finalidade de levantar dados de patologias que afetem fachadas de prédios da UFPa, utilizou-se a amostragem de 30 edificações, buscando-se quantificar um maior número de casos patológicos possíveis. Este número de amostras equivale a aproximadamente $35 \%$ do total das edificações, considerando que a Universidade encontra-se com obras em andamento, em que algumas edificações podem não ter sido contabilizadas.

Segundo Paladini (1995), uma amostra, que não é uma parte integrante de qualquer todo, é um conjunto de "peças" de um lote determinado segundo critérios pré-estabelecidos. Assim, definese uma amostragem de padrão homogêneo, com suas partes podendo ser comparadas entre si com garantia da representatividade.

Baseado nisso, e objetivando uniformidade de projetos tornando-os comparáveis entre si, a seleção dos estudos de caso obedeceu a critérios de escolha classificação quanto ao material a ser analisado e quanto à idade da edificação.

Foram selecionadas edificações (com auxílio do mapa do campus e visitas in loco) que apresentassem fachadas com revestimento cerâmico e/ou em argamassa e estrutura em concreto aparente, distinguidas em edificações antigas (década de 70), intermediárias (década de 80/90) e recentes (a partir dos anos
2000). Conforme Chew, Tan e Kang (2005), a idade da edificação dita a frequência e extensão do dano ocorrido; e os materiais são parâmetros significativos de análise, visto que a resistência do sistema afeta a envolvente.

\subsection{DEFINIÇÃO DE MÉTODOS PARA LEVANTAMENTO DE DADOS}

\subsubsection{Ficha de Identificação de Danos (FIDs)}

A NBR 5674 (ABNT, 1999) recomenda que as inspeções sejam orientadas por listas padronizadas, considerando um roteiro lógico que descreva a degradação de cada componente da edificação e avalie a perda do seu desempenho. Segundo Costa e Silva (2008), este procedimento é a etapa inicial de avaliação do problema, buscando-se maior número de informações para elucidar o dano.

Para se obter dados que quantifiquem a pesquisa, as visitas técnicas foram realizadas com auxílio de registro fotográfico e produção, individual para cada edificação, de Fichas de Identificação de Danos, de modo a detectar quais patologias estão presentes.

Esta FID funciona como um método sistemático e impessoal de inspeção visual, considerada, segundo Falorca e Mendes Silva (2009), como a caracterização do estado da edificação em que, para cada fachada, deve haver precisão de dados coletados. A partir da 
padronização dos pontos a serem observados durante as visitas in loco, da observação visual e das imagens fotográficas, registrou-se os danos identificados da envolvente. Desta maneira, a FID, representada por fotografias e desenhos técnicos, foi elaborada através de pranchas individuais em formato A3 (210 mm x $420 \mathrm{~mm}$ ), com o auxílio do software AutoCAD ${ }^{\circledR} 2012$ como ferramenta de projeto. Tinoco (2009) recomenta que estas fichas apresentem-se com tamanho apropriado e de rápida compreensão, de modo que seu manuseio técnico permita realização de ações seguras.

Por meio de fotos pontuais de patologias foram identificados os tipos de danos existentes nas edificações, mas não todas as suas localizações exatas, uma vez que o objetivo maior das fichas foi listar quais danos são corriqueiros, e não apontar o local preciso onde cada um deles acontece. A partir da amostragem e da reunião dos danos apresentados em tais fichas, pode ser realizado em momento posterior análise minuciosa para prédios em específico.

A partir dos dados destes documentos, foram produzidos gráficos para caracterizar a amostra. Para avaliar a significância dos resultados obtidos, procurou-se classificar o estado de conservação das edificações de modo a compreender como se encontra a situação física dos estudos de caso. A maioria dos autores utiliza análise qualitativa para estipular níveis de classificação, indo desde a melhor condição possível até o nível mais elevado de degradação.

Baseando-se em observações in loco, fichas e nas definições estipuladas por Terra (2001) e Paladini (1995), considerou-se a seguinte categorização para se referir ao estado físico das edificações:

- Bom: prédios sem lesões graves $^{5}$ apresentando apenas danos superficiais ${ }^{6}$, mas sem risco à integridade;

- Regular: prédios com princípio de alguma lesão mais grave, concentrando-se em uma situação intermediária perante os demais casos;

- Ruim: prédios em péssimo estado de conservação, apresentando, além de danos pontuais, grandes extensões de sua envolvente, com patologias afetando o material de forma definitiva, deteriorando esteticamente o sistema de revestimento.

\subsubsection{Mapa de Danos (MD)}

Para Barthel, Lins e Pestana (2009), os mapas representam graficamente as patologias existentes e registram a evolução do estado físico do prédio, já que uma vez efetuada a análise, servirá de base para futuras análises contra o avanço de patologias.

Após roteiro que facilitou o registro de informações (Fichas de Identificação de Dados), gerou-se um segundo instrumento (Mapas de Danos) a ser utilizado como pré-requisito na elaboração de projetos de intervenções, orientando a gestão da manutenção das edificações.

A partir da seleção de edificações em que se tenha interesse em realizar estudo mais aprofundado, pode-se realizar análise mais detalhada por meio dos Mapas de Danos, a partir dos quais se sugere intervenções de reparo. Estes foram propostos em pranchas individuais em formato A3-extendido (210 mm x $1.100 \mathrm{~mm}$ ) com o auxílio do software AutoCAD ${ }^{\circledR}$ 2012, em que a extensão do dano foi determinada com base em fotos e em inspeção visual.

\subsubsection{Estudo Comparativo de Frequência de Ocorrência de Danos}

A pesquisa contempla estudo comparativo da frequência de ocorrência dos danos (resumo conclusivo dos dados obtidos) das 30 edificações sintetizadas nas FIDs, verificando qual falha apresenta comportamento estatisticamente significativo em relação às demais. Como critério para quantificar os danos, cada tipo foi contabilizado como uma ocorrência.

\footnotetext{
${ }^{5}$ Considera-se, para a referente pesquisa, como lesão grave, aquele defeito que impede a utilização do produto para o fim a que se destina, ou diminui sua vida útil afetando sua eficiência.

${ }^{6}$ Considera-se, para a referente pesquisa, como dano superficial, aqueles defeitos menores que não atingem o desempenho do produto na sua função essencial.
} 
Estes pontos foram discutidos baseandose em uma pesquisa quantitativa, já que os dados estão traduzidos em números e informações que os classificam, evitando a subjetividade $e$ uniformizando uma abordagem capaz de obter dados comparáveis. Deste modo, as amostras, somadas a este estudo comparativo, permitem a obtenção de um panorama geral dos problemas patológicos mais decorrentes e as edificações com maior diversidade de danos. A partir disso, podese aprofundar os estudos em edificações específicas sobre possíveis causas de danos patológicos por meio de análise e interpretação dos dados previamente levantados.

\subsubsection{Outros Métodos}

Ao final, se o interesse da pesquisa estiver além da identificação de dados, é interessante que se apliquem métodos complementares que funcionam como prérequisito para diagnósticos mais técnicos, como os apresentados a seguir:

- Ensaios de caracterização de amostras: ensaios de complementação da pesquisa, com análise de pequenas amostras de materiais ou análises feitas in loco;

- Processos de intervenção: a partir dos dados obtidos, adquire-se subsídios para propor alternativas de recuperação para as edificações específicas.

\section{RESULTADOS}

Com base na produção de metodologia padronizada de análise, buscou-se apontar aqueles caminhos que deveriam ser seguidos em futuros laudos técnicos com a finalidade de recuperar fachadas deterioradas, utilizando-se como exemplo edificações presentes na UFPa.

\subsection{IDENTIFICAÇÃO DAS PRINCIPAIS PATOLOGIAS}

A partir da elaboração individual de 30 fichas de identificação de danos para as edificações em análise, produziu-se um documento que funcionou de base para inspeções de vistoria local, permitindo o registro da situação física das fachadas dos estudos de caso.

Por meio das FIDs desenvolveu-se uma análise global em como se encontram as fachadas pesquisadas quanto às patologias nelas presentes. Vale ressaltar que, para esta pesquisa, o conceito dado à patologias trata-se de tudo aquilo que depõe contra a imagem física da instituição, seja provocado pelo tempo ou por ações provenientes de causa humana. A representação gráfica da ficha pode ser observada por meio da Figura 2, com campos distribuídos da seguinte forma:

- título, apontando a edificação em análise com registro da data de vistoria;

- levantamento fotográfico, separado por fachadas, com indicação dos danos presentes. Onde houve necessidade, fezse fotos mais detalhadas de cada ponto;

- legenda com numeração individual das patologias encontradas;

- características da edificação, com classificação da idade (recente, intermediária ou antiga) e do material (revestimento cerâmico, argamassa e estrutura de concreto aparente) em análise;

- implantação da edificação dentro do campus, conforme setor onde se encontra (básico, profissional ou saúde), apontando a situação física do edifício quanto a localização e contextualização urbana atual;

- planta baixa, com indicação de áreas, cotas e fachadas analisadas;

- orientação solar da edificação, conforme mapa da cidade de Belém.

\subsubsection{Caracterização das Edificações}

A partir dos dados obtidos com as FIDs, caracterizou-as as edificações em categorizações do tipo Bom, Regular e Ruim. 


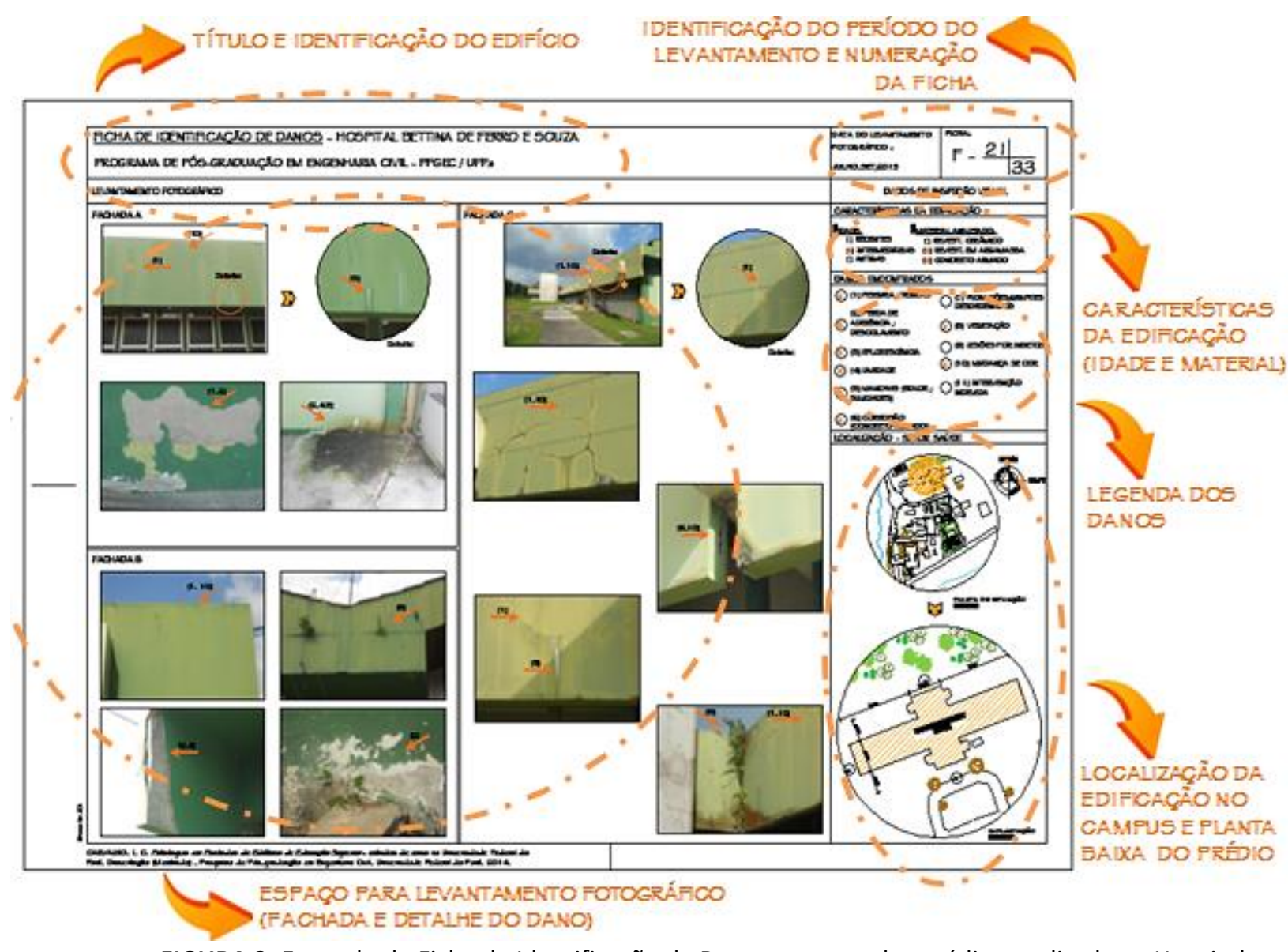

FIGURA 2: Exemplo de Ficha de Identificação de Danos para um dos prédios analisados - Hospital Universitário Bettina de Ferro e Souza.

Notou-se que 60\% (Regular) das 30 edificações apresentam-se com princípio de alguma lesão mais grave, concentrando-se em situação intermediária perante as demais. Já $23 \%$ delas classificam-se em Ruim, ou seja, prédios em péssimo estado de conservação com grandes extensões de patologias em sua envolvente, as quais afetam o material de forma definitiva e deterioram esteticamente o sistema de revestimento. E por fim, representando cerca de $17 \%$ dos casos, estão as edificações consideradas em Bom estado, apresentando danos superficiais e ausência de lesões mais graves, sem risco a integridade. A atribuição dada para este último caso, não significa dizer que os prédios estejam isentos de qualquer tipo de patologias, apenas apresentam um nível mínimo aceitável de desempenho (Figura 3).

Cada categorização citada foi relacionada com a idade dos estudos de caso. Dentro dos $17 \%$ das edificações consideradas em bom estado de conservação, todas são enquadradas como Recentes (Figura 4); dos $60 \%$ das edificações classificadas como regulares, metade são prédios Antigos, seguidos dos intermediários com 28\% (Figura 5); e 23\% das edificações ditas como ruins, $72 \%$ estão destinados às edificações Intermediária, e o restante distribuído igualmente entre Antigas e Recentes (Figura 6).

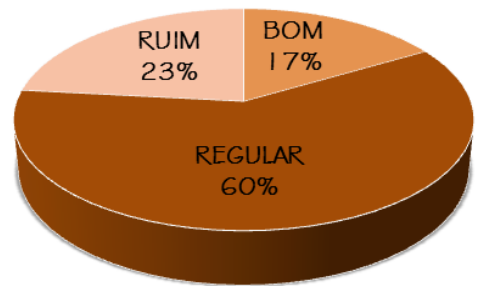

FIGURA 3: Estado de Conservação das edificações BOM - $17 \%$

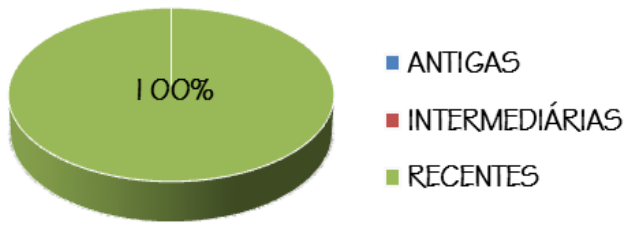

FIGURA 4: Classificação da Categoria Bom. 
REGULAR - $60 \%$

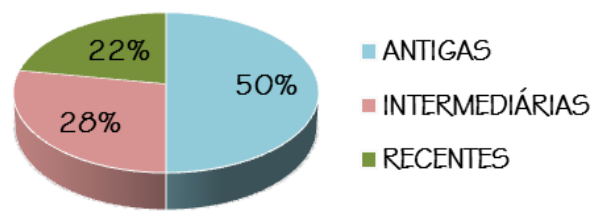

FIGURA 5: Classificação da Categoria Regular.

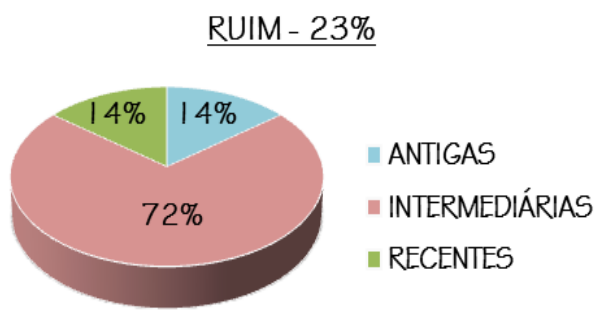

FIGURA 6: Classificação da Categoria Ruim.

De acordo com os gráficos, as edificações com idade antiga e intermediária ocupam grande parte da porcentagem das piores categorizações (Ruim e Regular), com as edificações que apresentam Bom estado concentrando apenas nas recentes. Esta situação provavelmente se deve, à reformas e ao menor tempo de vida útil (recentes) e à falta de prevenção em período hábil contra a ocorrência de danos (antigas e intermediárias). Como constatado, as edificações mantém seu estado de conservação durante os primeiros anos e, com o passar do tempo, perdem suas características iniciais de forma mais acelerada em virtude da ausência de procedimentos de manutenção que preservem seu estado físico o quanto possível.

\subsubsection{Mapas de Danos}

Após quantificar dados e obter informações do estado físico das edificações por meio de Fichas, é possível também realizar análises aprofundadas para edificações em específico conforme interesse. Para a presente pesquisa, isso foi expresso em mapas de danos de fachadas pertencentes ao Instituto de Ciências Biológicas, os quais estabeleceram conexões entre as diferentes partes das fachadas com os tipos de patologias, delimitando sua localização exata e facilitando encontrar suas causas.

Os mapas representaram graficamente as patologias existentes e registram a evolução do estado físico do prédio, já que uma vez efetuada a análise, servirá de base para futuras análises contra o avanço de patologias (BARTHEL, LINS E PESTANA, 2009). A representação gráfica dos mapas pode ser observada por meio da Figura 7, com campos distribuídos da seguinte forma:

- título, apontando a edificação em análise com registro da data de vistoria;

- planta baixa da edificação analisada, com identificação das fachadas;

- representação gráfica com marcação da extensão das patologias (região danificada) a partir do levantamento geométrico da fachada, em que cada dano é representado a partir de códigos. Optou-se por hachuras com cores para facilitar entendimento dos danos presentes, já que a maioria deles se sobrepõe uns aos outros;

- uso de imagens fotográficas, para facilitar a visualização do dano;

- intervenções genéricas (ações corretivas que devem ser munidas de fundamentação teórica), com sugestões pontuais de reparação para a respectiva fachada. Para abordagens mais aprofundadas necessita-se de um relatório técnico;

- e indicação dos pontos onde foram feitos os ensaios.

De posse dos mapas, é possível apontar as principais causas a partir do ponto exato onde se encontra o dano, efetuando diagnóstico para esclarecer o que motivou a queda de desempenho dos revestimentos; para então, definir em seguida procedimentos de intervenção para o Instituto. Isso vai ao encontro da pesquisa realizada por Pereira (2012), o qual afirma que o mapa de danos tem a finalidade de assegurar o conhecimento das degradações, oferecendo suporte às intervenções de conservação, ao levantamento de custos, às visitas, às inspeções e aos serviços de manutenção.

\subsubsection{Registro da frequência de ocorrência dos danos e visão sistêmica das principais patologias}

A classificação dos mecanismos de 
degradação, relacionando-os com seus respectivos agentes causadores, fornece subsídios para posteriores reparos, apresentando principais anomalias e suas causas, ressaltando que dentro deste campo de estudo também podem existir outros tipos não citados. A partir da Tabela 1 a seguir, estabeleceuse os principais mecanismos de degradação, com suas respectivas causas, para os estudos de caso da UFPa.

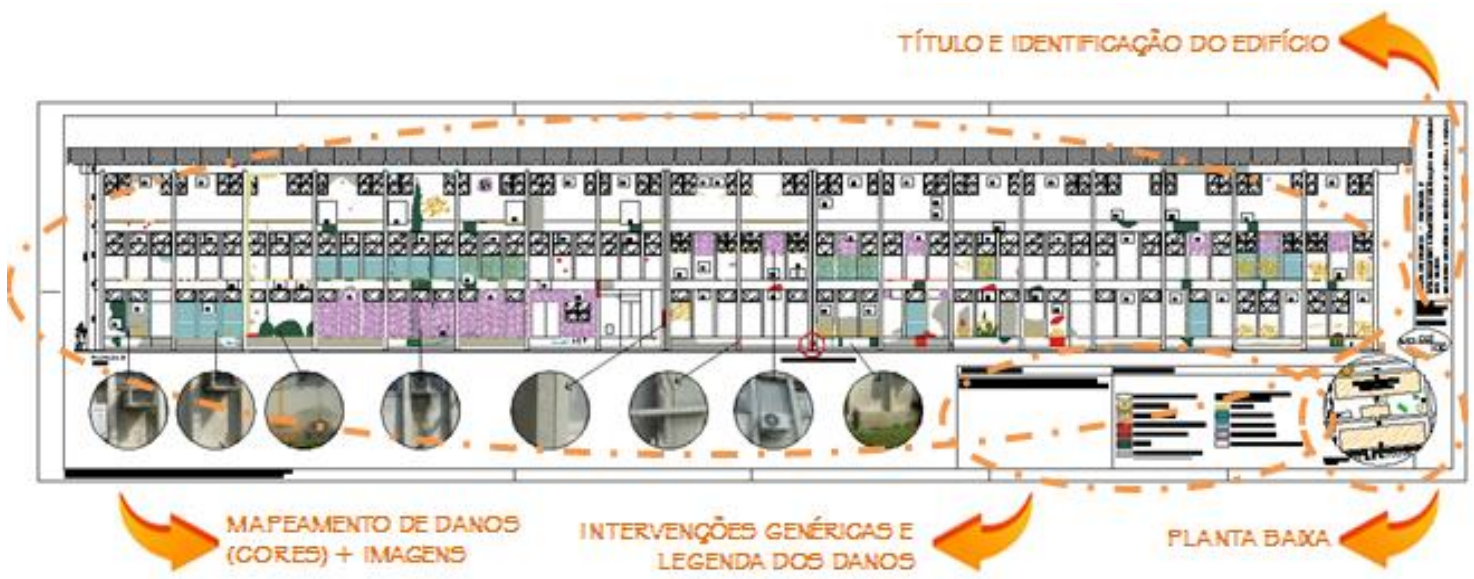

FIGURA 7: Exemplo de um Mapa de Danos de uma das fachadas do Instituto de Ciências Biológicas.

\begin{tabular}{|c|c|c|c|}
\hline \multirow{2}{*}{$\begin{array}{l}\text { Principais mecanismos de degradação } \\
\text { (patologias) }\end{array}$} & \multicolumn{3}{|c|}{ Agentes de degradação $^{7}$} \\
\hline & Causas atmosféricas & Causas biológicas & Causas Adquiridas \\
\hline Fissuras e trincas & $\bullet$ & & $\bullet$ \\
\hline Perda de aderência/descolamento & $\bullet$ & & $\bullet$ \\
\hline Eflorescência & $\bullet$ & & $\bullet$ \\
\hline Umidade & $\bullet$ & & $\bullet$ \\
\hline \multicolumn{4}{|l|}{$\begin{array}{l}\text { Manchas (colonização } \\
\text { biológica/sujidade) }\end{array}$} \\
\hline Corrosão (concreto armado) & $\bullet$ & & $\bullet$ \\
\hline Vegetação & & $\bullet$ & $\bullet$ \\
\hline Intervenção indevida & & & $\bullet$ \\
\hline Fissuras e trincas & & & $\bullet$ \\
\hline Macro-organismos & & $\bullet$ & \\
\hline Manchas & \multirow{5}{*}{\multicolumn{3}{|c|}{ Umidade }} \\
\hline Perda de coloração & & & \\
\hline Corrosão (concreto armado) & & & \\
\hline Eflorescência & & & \\
\hline Descolamento & & & \\
\hline
\end{tabular}

\footnotetext{
7 Classificação baseada em ASTM E632, 1998; MÜLLER, 2010; LERSCH, 2003 e MORAES, 2007. Também são usadas outras nomenclaturas para classificar os agentes de degradação, subdividindo-os, por exemplo, em agentes físicos, químicos e biológicos, como nas pesquisas de Torraca (1981).
} 
Os dados obtidos a partir da Tabela 1 e dos documentos produzidos, foram submetidos a uma análise estatística que, assim como na pesquisa de Brito e Neto (2012), proporcionaram conclusões para aplicar ações de prevenção de danos em sistemas de revestimento, de modo a alcançar fachadas de melhor qualidade e menos onerosas.

Os resultados do gráfico (Figura 8), que totalizam 204 ocorrências, evidenciam que os tipos de danos mais frequentes são fissuras/trincas (15\%), perda de aderência/descolamento (14\%), umidade (14\%) e manchas (15\%), os quais praticamente equiparam-se. Em segundo plano, segue depósito de macro-organismos (11\%), corrosão em estrutura de concreto armado (8\%), presença de vegetação (8\%), e, por fim, intervenção indevida (7\%) provocada pela ação humana e perda de coloração do revestimento (5\%). Outros tipos de patologias, como eflorescência e pichações/grafites desordenados, foram pouco significativos, representando $1 \%$ dos casos estudados.

Este comportamento também foi observado por Lourenço, Luso e Almeida (2006), os quais desenvolveram pesquisa que vai ao encontro desta quando, para fachadas submetidas às mesmas condições ambientais (chuvas intensas/ganhos solares em determinada época do ano), foram detectados danos patológicos semelhantes - patologias estruturais, descolamento da pintura, fissuras, fungos, vegetação, formação de bolhas nas películas de tinta e manchas nas paredes ao nível do solo (biodeterioração em virtude da umidade; e sujidades provenientes da fixação de partículas atmosféricas).

Percebe-se que um dano pode dar início a outros, o que é evidenciado por meio daqueles índices de ocorrência que se equiparam na Figura 8, ou seja, a presença de fissuras facilita a penetração de água para o componente, propiciando corrosão do aço do concreto armado, bem como descolamento de revestimento em argamassa; a umidade causa manchas na envolvente, facilitando fixação de partículas atmosféricas; e perda do revestimento em virtude da presença de umidade local, gerando um sistema deficitário.

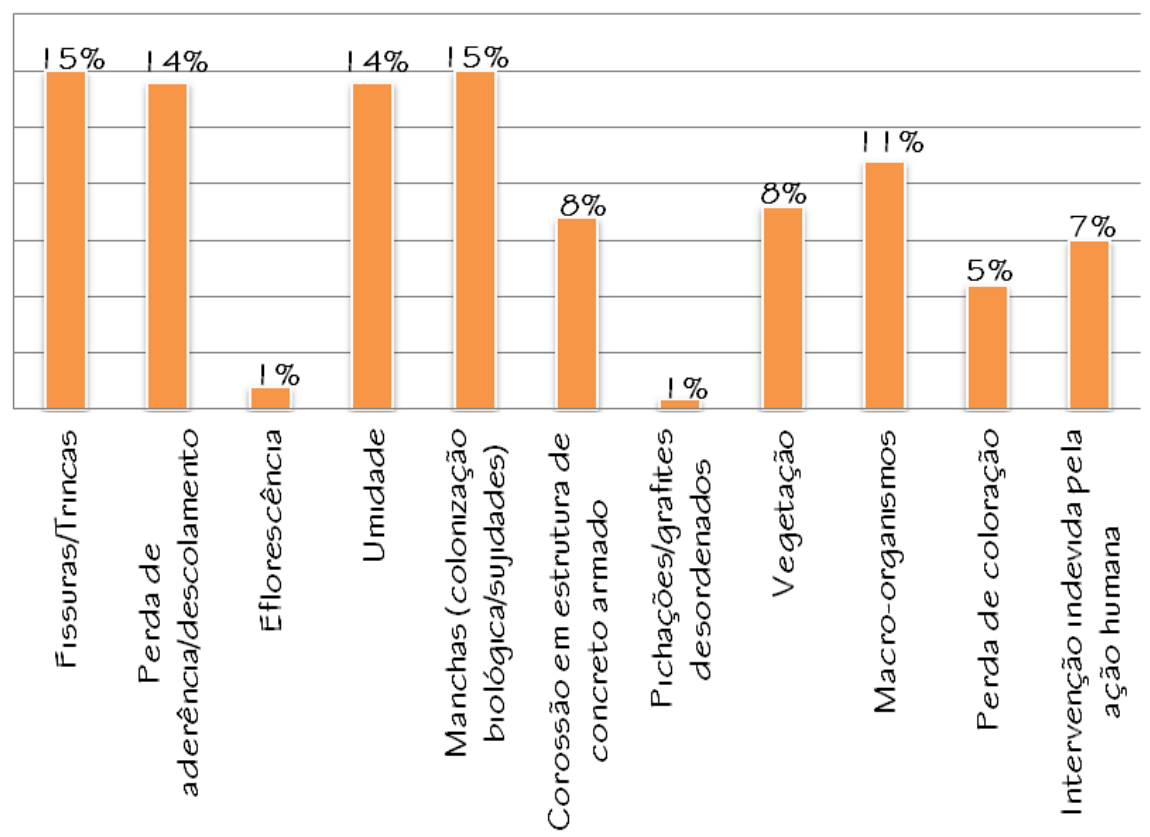

FIGURA 8: Gráfico da frequência de ocorrência dos mecanismos de degradação. 
A Tabela 2 apresenta as 30 edificações utilizadas como estudos de caso (divididas por idade de projeto), ilustrando algumas patologias encontradas (conforme nomenclatura de dados expostos no gráfico da Figura 8) de acordo com o material do revestimento externo. As imagens, fotografadas de Novembro a Dezembro de 2013, são algumas das utilizadas para montar as Fichas de Identificação de Danos.

\section{TABELA 2: Exemplos de danos presentes nos estudos de caso conforme tipo de revestimento externo.}

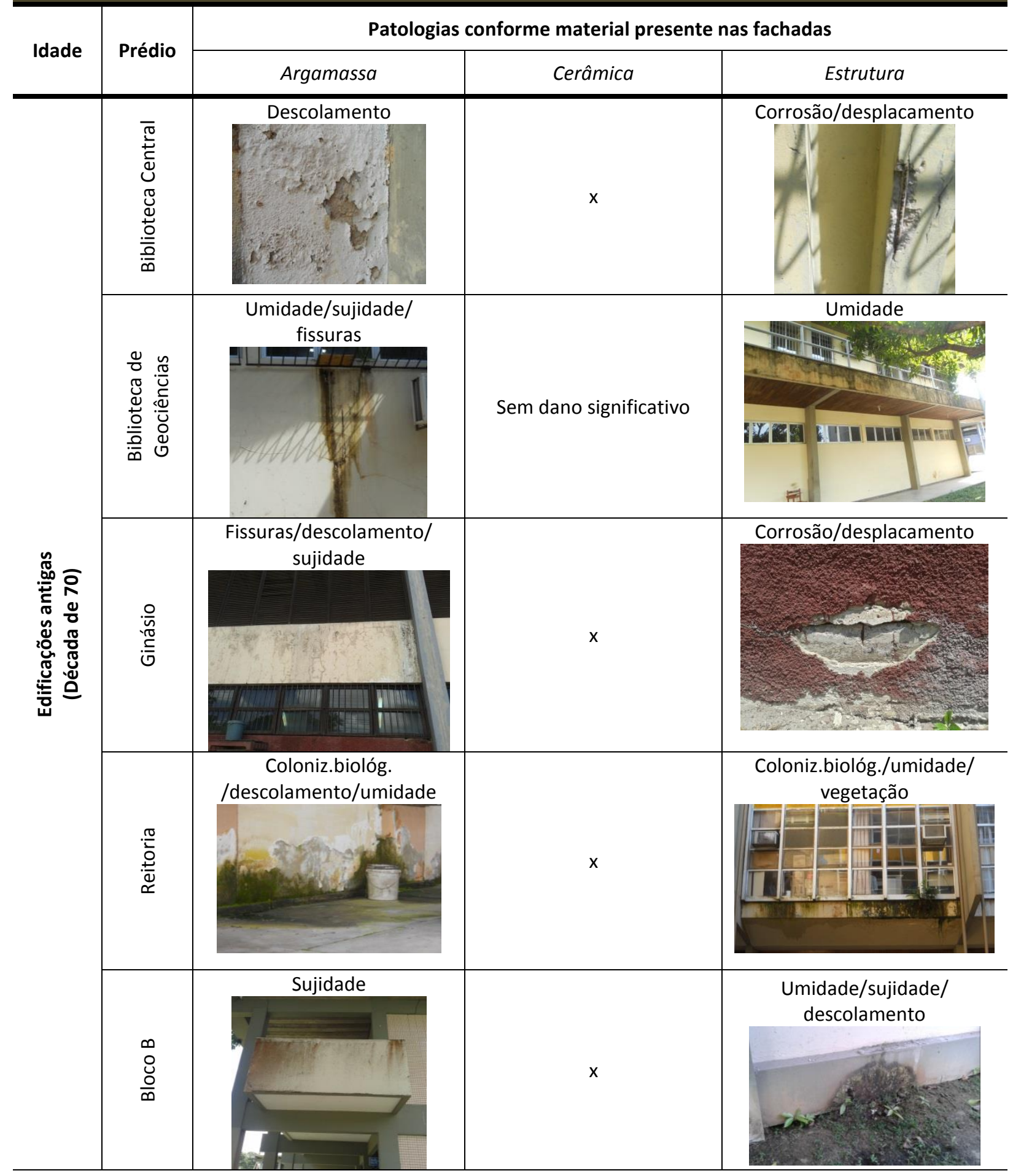


TABELA 2: Exemplos de danos presentes nos estudos de caso conforme tipo de revestimento externo. (Continuação).

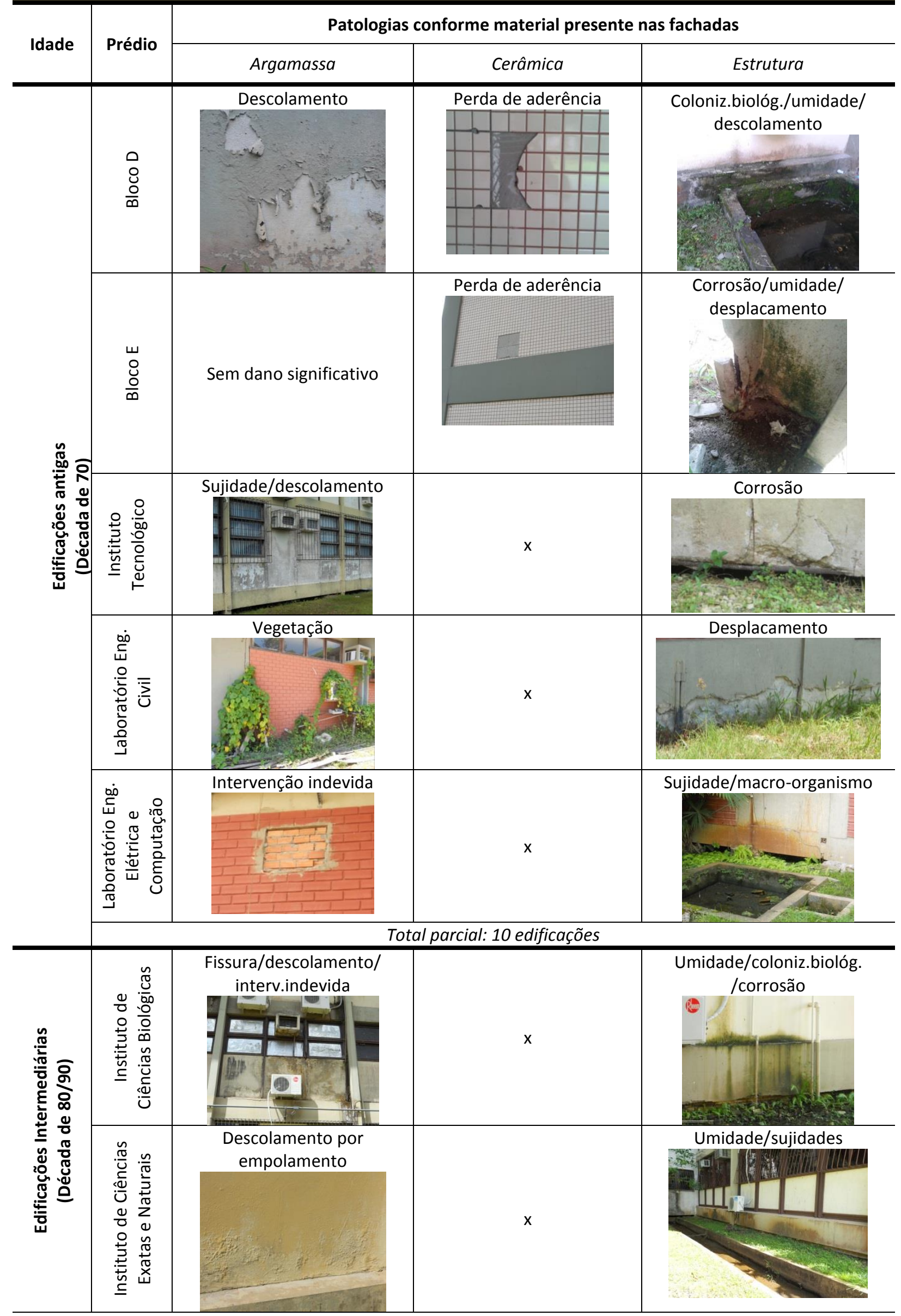




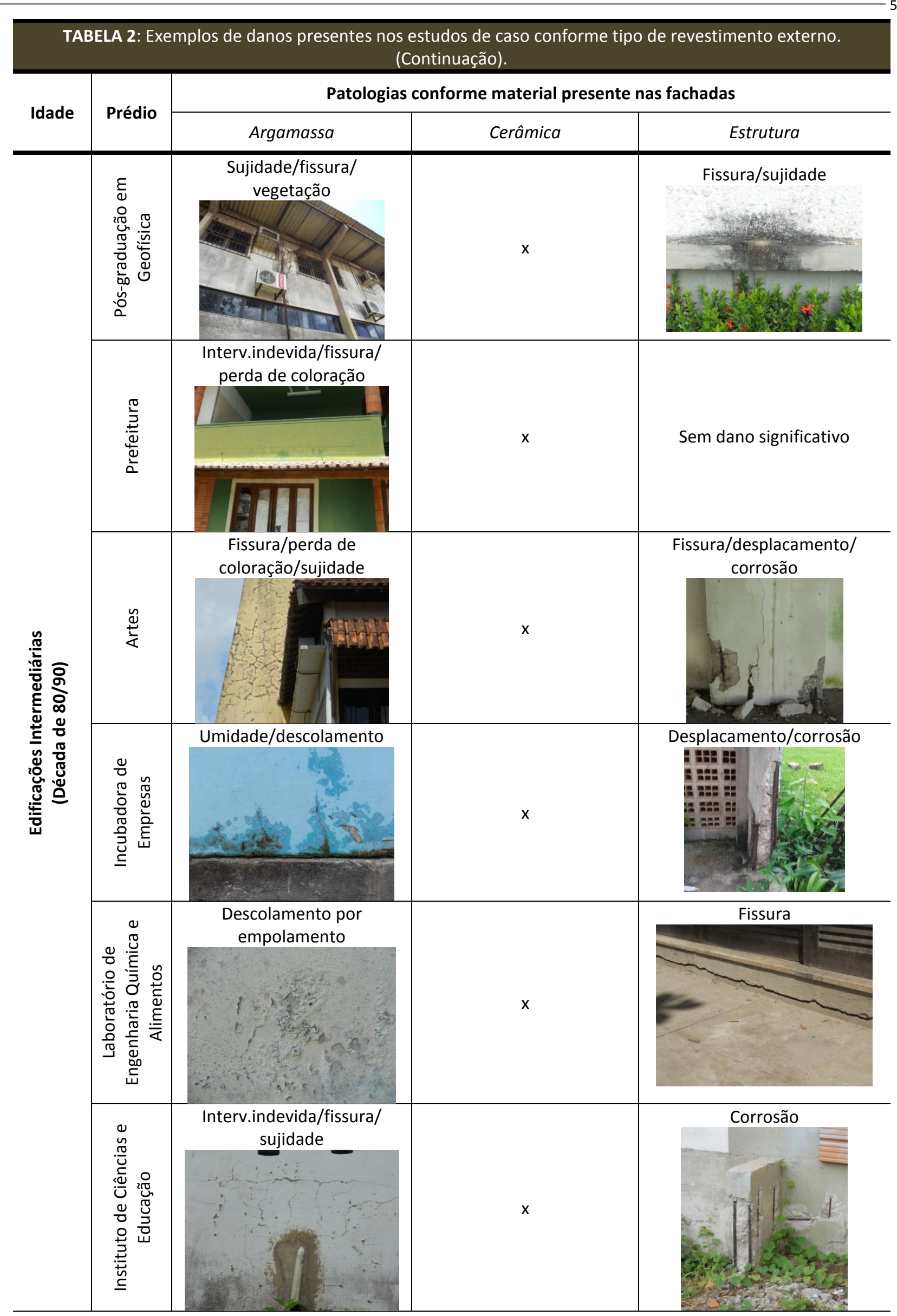




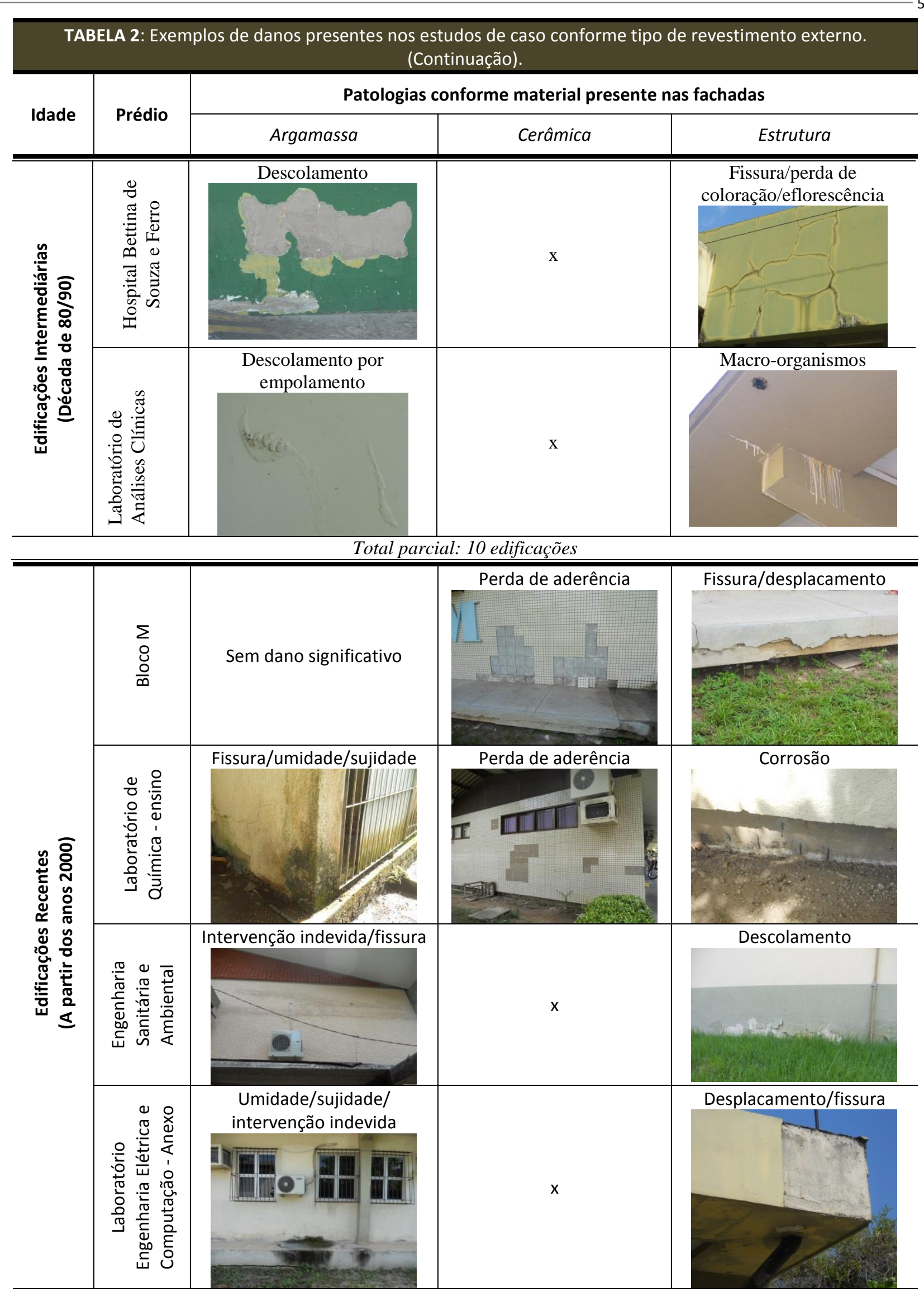


TABELA 2: Exemplos de danos presentes nos estudos de caso conforme tipo de revestimento externo. (Continuação).

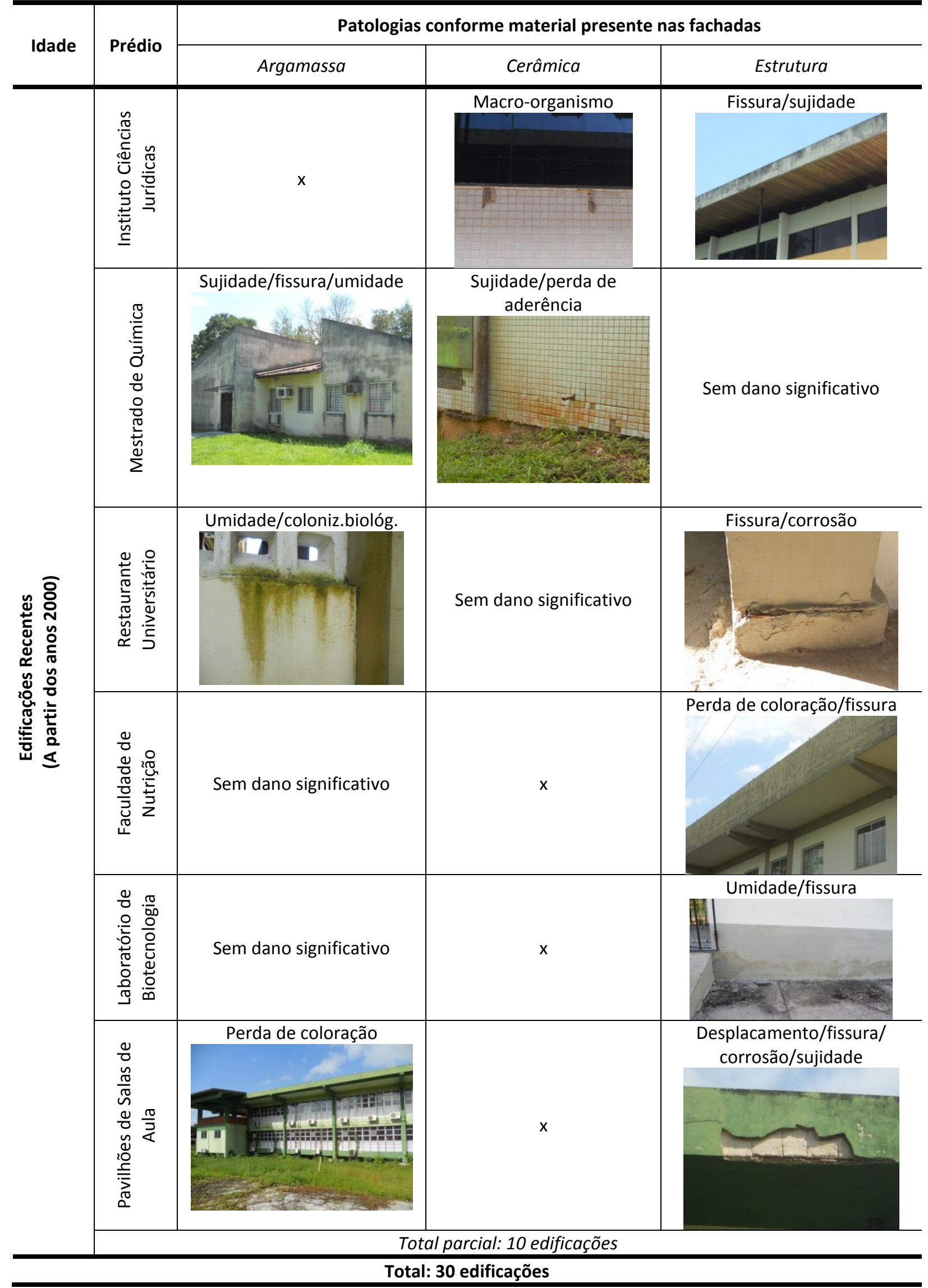

(x) Marcação que indica que a edificação não apresenta tal material em sua composição. 
Percebeu-se que na Universidade acontecem intervenções emergenciais sem planejamento prévio. A partir dos resultados, é evidente que a incidência corriqueira destas patologias se deve, principalmente, à falta de um sólido programa de manutenção periódica para os edifícios mais antigos, já que estão sujeitos a sofrer ação do uso e de agentes externos; ou a erros de processo executivo e/ou de projeto, observado nas edificações construídas recentemente ou aquelas que aparentemente sofreram algum tipo de reforma.

Considerando que alguns mecanismos de degradação tem relação entre si, pois as patologias raramente acontecem individualmente, as causas (atmosféricos, biológicos ou adquiridos) atribuídas a cada dano devem ser avaliadas individualmente, visto que a identificação de hipóteses da origem do problema direciona à busca de soluções mais precisas e definitivas.

\subsubsection{Outros Métodos}

Cita-se outros dois instrumentos necessários para finalizar a metodologia de análise padronizada para inspeções em fachadas, como forma de contribuição para a melhoria de edificações. Se o interesse estiver em ir além da identificação de dados, é interessante que se apliquem métodos complementares que funcionam como pré-requisito para diagnósticos mais técnicos, como os apresentados a seguir:

a) Ensaios de caracterização de amostras:

Podem ser realizadas investigações pontuais (ensaios laboratoriais com pequenas amostras ou análises feitas in loco com equipamentos específicos) que complementem a pesquisa ou comprovem as origens daqueles danos patológicos que a primeira vista não se conseguiu identificar a causa, auxiliando na tomada de decisões quanto à intervenção.

\section{b) Processos de intervenção:}

Uma vez corrigida e anulada a causa de um componente, pode-se devolver a ele seu aspecto e funcionalidade anteriores. É interessante adotar procedimentos com resultados que se mantêm a longo prazo, com a edificação preservando estado satisfatório por um período maior. A alternativa mais adequada também deve considerar 0 ambiente em que a edificação encontra-se inserida e as ações naturais do meio que está sujeita.

As soluções são diversificadas, não existindo uma única medida corretiva. Portanto, como não se deve dedicar a todas as anomalias a mesma atenção em virtude da complexidade que cada uma apresenta, os reparos físicos devem contemplar a urgência de cada caso, optando-se pelo mais conveniente conforme custos, funcionalidade e durabilidade.

Considerando o nível de concepção e execução da fachada, as condições ambientais do meio externo, as condições de uso e o nível de manutenção, afirma-se que o processo de recuperação de fachadas pode tornar-se complexo e demorado, necessitando de análises aprimoradas (SILVA, BRITO e GASPAR, 2011) para apontar os tipos de intervenção. Mediante isso, cabe à presente pesquisa informar os caminhos básicos para futuros laudos, com produção de documentos conclusivos sobre o comportamento da edificação.

Após a edificação ter seus danos identificados (FIDs) com apresentação do mapeamento dos locais exatos onde se encontram (Mapas de Danos), bem como com índices das patologias mais corriqueiras e uso de ensaios técnicos, pode-se elaborar um documento técnico conclusivo, que apresente:

- dados pessoais do requerente e requerida;

- objetivo do documento: após verificar surgimento de patologias na fachada de determinada edificação de interesse, contratase profissional técnico habilitado com 0 propósito de, após identificados os danos e apontadas suas causas, relatar soluções técnicas e planos de recuperação para sanar as patologias;

- considerações técnicas sobre localização e características físicas do imóvel (materiais analisados, tipo de uso, quantidade de pavimento, dentre outros);

- recomendações de reparo: intervenção individual para cada patologia encontrada, subdividida em hipótese de diagnóstico, em 
que se identificam as causas prováveis de suas anomalias; e propostas de intervenção, em que se propõe alternativas de recuperação, consideradas como medidas aplicáveis também em projetos futuros, observando a especificidade de cada caso.

- Anexos e/ou apêndices: normas técnicas e referências bibliográficas utilizadas; sugestão de especificações de materiais; possíveis ensaios laboratoriais ou in loco, sempre que houver necessidade de experimentos que ofereçam ao relatório conclusões mais técnicas; levantamento fotográfico, com inserção de imagens digitalizadas ao longo do documento (ou em seguida dele). Se necessário, anexar pareceres de outros profissionais, que, por exemplo, ofereçam relatórios que comprovem se a estrutura está condenada ou documentação de planilha orçamentária com quantitativo de custos e materiais para executar os reparos necessários.

\section{CONSIDERAÇÕES FINAIS}

Visando produzir um padrão de metodologia avaliativa de levantamento de danos em fachadas, de modo a adquirir subsídios em futuras intervenções corretivas, partiu-se de exemplos de patologias presentes no envelope externo de 30 edificações da UFPa. Baseando-se a priori em levantamento visual e quantificação dos danos por meio do registro de anomalias (Fichas de Identificação de Danos), gerou-se uma série de documentos capazes de permitir futuros gerenciamentos de manutenção e programações de reparos.

A presença das patologias, discursadas ao longo da pesquisa e presentes na amostra, acarretou consequências para a edificação como um todo. A partir de registro da frequência de ocorrência de danos, observou-se que vários danos acontecem simultaneamente dando origem a outros, com sua ocorrência relacionada a uma ou várias causas e com situações de fácil identificação e outras não.
Pode-se produzir Mapas de Danos para aqueles prédios de maior interesse, originando registro com precisão das áreas afetadas, o que facilita apontar suas causas. Baseando-se nas afirmações de Tinoco (2009), por meio deste método é possível caracterizar o estado físico da edificação através de sua representação gráfica/fotográfica, abrangendo levantamento dos danos identificados, ilustrando-se e discriminandose os agentes que originaram as patologias. Para auxiliar na tomada de decisões quanto à intervenção, também sugere-se que sejam efetuadas investigações por meio de ensaios laboratoriais ou in loco, os quais testemunham a garantia da qualidade do serviço.

Concluiu-se que os casos da UFPA precisam ser conduzidos à recuperação de seus componentes externos, considerando seu desempenho insatisfatório frente à capacidade de promover a estanqueidade e proteção de agentes agressivos. Portanto, de modo a evitar o aparecimento precoce de patologias em fachadas, elevando seu tempo de vida útil e reduzindo custos extras, sugere-se, além da execução rigorosa baseada em normas técnicas, a programação de vistorias periódicas para que medidas preventivas de reparo sejam tomadas.

Assim, percebe-se que com esta organização de levantamento dos dados, consegue-se subsídios para o objetivo maior da produção dos documentos: ter base consistente para apontar hipóteses de diagnóstico e e afirmar a necessidade de propostas de intervenção. Percebeu-se que não existe um único rumo avaliativo, cabendo à presente pesquisa apontar os caminhos básicos para tal, em que resultados obtidos não devem ser tomados como verdade absoluta, mas sim está aberto à inserção de novas sugestões para incrementar todas as etapas.

\section{AGRADECIMENTOS}

À Coordenação de Aperfeiçoamento de Pessoal de Nível Superior - CAPES, pelo apoio financeiro. 


\section{REFERÊNCIAS BIBLIOGRÁFICAS}

AMERICAN SOCIETY FOR TESTING AND MATERIALS. Standard Practice for Developing Accelerated Test to Aid Prediction of the Service Life off Building Components and Materials. E 632-82 (Reaproved 1996). Annual Book of ASTM Standards, section 14, v.1402, Philadelphia, 1998.

ASSOCIAÇÃO BRASILEIRA DE NORMAS TÉCNICAS. NBR 5674/1999 - Manutenção de Edificações Procedimento. Rio de Janeiro, 1999.

ASSOCIAÇÃO BRASILEIRA DE NORMAS TÉCNICAS. NBR 15575-1/2013 - Edificações habitacionais Desempenho. Parte 1: Requisitos gerais. Rio de Janeiro, 2013.

BARROS, Mercia Maria Semensato Bottura de; SABBATINI, Fernando Henrique. Produção de Revestimentos Cerâmicos para paredes de vedação em alvenaria: diretrizes básicas. São Paulo, EPUSP-PCC, 2001.

BARTHEL, C.; LINS, M.; PESTANA, F. O papel do mapa de danos na conservação do patrimônio arquitetônico. In: Congresso Iberoamericano y VIII Jornada "Técnicas de Restauración e Conservación Del Patrimônio", 2009. La Plata, Buenos Aires, Argentina. 20 p.

BRASIL. Lei no 8.666, de 21 de junho de 1993, que regulamenta o art. 37 , inciso XXI, da Constituição Federal, institui normas para licitações e contratos da Administração Pública e dá outras providências.

BRITO, Jorge de; NETO, Natalia. Buildings envelope anomalies: Validation of an inspection and diagnosis system for anomalies in natural stone cladding. Construction and Building Materials, Elsiever, v. 30, 224-236, 2012.

CHEW, M. Y. L; TAN, S. S.; KANH, K. H. Contribution Analysis of Maintainability Factors For Cladding Facades. Architectural Science Review, v. 48, n. 3, 215227, 2005.

CINTRA, Carlos Roberto Godoi. A utilização na ISO 6241 na avaliação de Edificações Escolares, através dos métodos e técnicas da APO - Avaliação Pós-ocupação - O Caso das "Escolas de Cara Nova" de Mogi das Cruzes. 2001. 142p. Dissertação (Mestrado) - Escola Federal de Engenharia de Itajubá (EFEI), Itajubá, 2001.

COSTA e SILVA, Angelo Justa da. Método para gestão das atividades de manutenção de revestimentos de fachada. 2008. 239p. Tese (Doutorado) - Escola Politécnica, Universidade de São Paulo, São Paulo, 2008.
COSTA JÚNIOR, Milton Paulino da. Avaliação pósocupação e manutenção estratégica de escolas públicas. 2001. 152 p. Dissertação (Mestrado) Programa de Pós-graduação em Engenharia Civil Universidade Federal do Espírito Santo, Vitória, 2001.

FALORCA, Jorge; MENDES SILVA, J.A.R. A model plan for buildings maintenance with application in the performance analysis of a composite facade cover. Construction and Building Materials. Elsiever, V. 23, n. 10, 3248-3257, 2009.

FLORES-COLEN, Inês; BRITO, de Jorge. A system approach for maintenance budgeting of buildings facades based on predictive and preventive strategies. Construction and Building Materials. Elsiever, V. 24, n. 9, 1718-1729, 2010.

LERSCH, Inês Martina. Contribuição para a identificação dos principais fatores e mecanismos de degradação em edificações do patrimônio cultural de Porto Alegre. 2003. 185p. Dissertação (Mestrado) Programa de Pós-graduação em Engenharia Civil da Universidade Federal do Rio Grande do Sul, Porto Alegre, 2003.

LOURENÇO, Paulo B; LUSO, Eduarda; ALMEIDA, Manuela G. Defects and moisture problems in buildings from historical city centres: a case studying in Portugal. Building and Environment, V. 41, 223-234, 2006.

MORAIS, Ana Isabel Barbosa. Soluções de reabilitação de fachadas com revestimento em ladrilhos cerâmicos. 2007. 170p. Dissertação (Mestrado) - Escola de Engenharia, Universidade do Porto, Porto, 2007.

MÜLLER, Siomara Ribeiro. Histórico do campus e as patologias das fachadas dos prédios voltados para Avenida Roraima - UFSM. 2010. 120p. Dissertação (Mestrado) - Programa de Pós-graduação em Engenharia Civil, Universidade Federal de Santa Maria, Santa Maria, 2010.

PALADINI, Edson Pacheco. Gestão da Qualidade do Processo: a qualidade na produção de bens e serviços. São Paulo: Atlas, 1995, 286p.

PEREIRA, Luciana Manzoni. Avaliação das Patologias e da Biodeterioração na Biblioteca Central Da UFSM. 2012. 126p. Dissertação (Mestrado) - Programa de PósGraduação em Engenharia Civil e Ambiental Universidade Federal de Santa Maria, Santa Maria, 2012.

RODRIGUES, M. Fernanda S.; TEIXEIRA, José M. C.; CARDOSO, José C. P. Buildings envelope anomalies: A visual survey methodology. Construction and Building Materials, Elsiever, v. 25, 2741-2750, 2011. 
SILVA, A.; BRITO, J. de; GASPAR, P. L;. Service life prediction model applied to natural stone wall claddings (directly adhered to the substrate). Construction and Building Materials, Elsiever, v. 25, 3674-3684, 2011.

TERRA, Ricardo Curi. Levantamento de Manifestações Patológicas de Fachadas das edificações da Cidade de Pelotas. 2001. 133p. Dissertação (Mestrado) Programa de Pós-graduação em Engenharia Civil Universidade Federal do Rio Grande do Sul, Porto Alegre, 2001.

TINOCO, Jorge Eduardo Lucena. Mapa de danos: Recomendações básicas. Centro de estudos avançados da conservação integrada - CECl. Olinda, Pernambuco, 2009, vol. 43. 23p.

TORRACA, Giorgio. Porous building materials: materials science for architectural conservation. Rome: ICCROM, 1981. 